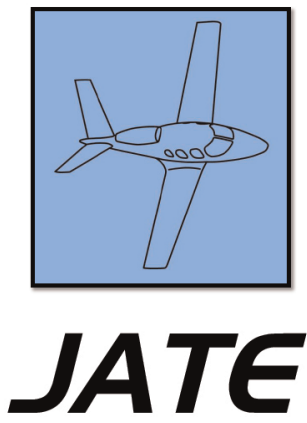

Journal of Aviation Technology and Engineering 4:1 (2014) 20-31

\title{
Loss of Control and Instrument Proficiency: A Case Study of a GA Pilot's Loss of Control While Operating in Instrument Meteorological Conditions
}

\author{
William Jeffrey "Jeff" Edwards
}

St. Louis University

\begin{abstract}
General Aviation (GA) safety is influenced and affected by choices pilots make with respect to their instrument proficiency and currency. Quantitative research on the instrument proficiency issues indicates a correlation between recent instrument experience and pilot skill. However, there is very little qualitative research on the subject. Qualitative research contributes to understanding the underlying issues and themes that contribute to loss of control accidents while operating in instrument meteorological conditions. This qualitative case study explores factors involving pilot instrument proficiency in a general aviation loss of control accident. These factors include pilot logbook irregularities, checklist usage, aircraft systems knowledge, pilot training, and pilot proficiency.
\end{abstract}

Keywords: instrument proficiency, loss of control, autopilot, general aviation, weather-related loss of control, pilot instrument proficiency, checklist, checklist usage

\section{Introduction}

Almost one half of all General Aviation (GA) fatal accidents are the result of loss of control (General Aviation Joint Steering Committee, 2012). Approximately $14 \%$ of the loss of control accidents occur to instrument-rated pilots flying in instrument meteorological conditions (IMC) (Fanjoy \& Keller, 2013; General Aviation Joint Steering Committee, 2012).

\section{About the Author}

William Jeffrey "Jeff" Edwards, holds a B.A. from Miami University, an M.A. from Ohio State University, and is a doctoral student at Saint Louis University. He is a retired U.S. Navy A-6 bombardier/navigator as well as a flight instructor and aircraft accident investigator. He is a member of the General Aviation Joint Steering Committee working group, researching general aviation safety. Edwards's research interests include improving general aviation safety. Correspondence concerning this article should be sent to vtailjeff@aol.com.

\section{Author Note}

I wish to thank Dr. Stephen Belt and Dr. Danielle Davis at Saint Louis University and Dr. Richard Fanjoy at Purdue University for reviewing this manuscript. I sincerely appreciate their time helping make this a better body of research. I also thank David Saracino for his assistance with graphics and Jennifer Gritton with her research assistance. 
These accidents have resulted in hundreds of fatalities over the last decade. Investigations reveal that some of these pilots do not meet instrument currency requirements to legally act as pilot in command while operating under instrument flight rules, others may have little to no recent actual instrument experience, and some have been advised to not fly under Instrument Flight Rules (IFR).

\section{Literature Review}

There have been a number of studies conducted over the last fifty years researching the issues related to pilot instrument currency, instrument proficiency, and weatherrelated accidents. Several studies largely focused on pilot instrument flying skills (Mengelkoch, Adams, \& Gainer, 1971; Wright, 1973; Casner, Geven, Recker, \& Schooler, 2014). Some concentrated on Part 121 air carrier pilots and the erosion of instrument hand-flying skills (Mitchell, Vermeulen, \& Naidoo, 2009; Casner, Geven, Recker, \& Schooler, 2014). Two quantitative studies measured pilot deviations from heading, altitude, or airspeed while flying in simulators or simulated instrument conditions (Mengelkoch, Adams, \& Gainer, 1971; Casner, Geven, Recker, \& Schooler, 2014).

Another study investigated military pilot instrument skills via survey methodology (Wright, 1973). One general aviation (GA) study conducted by the National Transportation Safety Board (NTSB) looked broadly at weather-related GA accidents and risk factors but did not examine pilot instrument currency data or pilot proficiency (NTSB, 2005). Another NTSB study researched glass cockpit GA safety and IMC operations but did not collect or analyze pilot currency or training (NTSB, 2010). While each study cited here provides insight into some of the issues of GA instrument flying skill and proficiency, none focused on the relationships between instrument flying skills, currency, proficiency, and loss of control accidents involving GA pilots while flying in IMC. This is in part due to the nature of the studies themselves. Many of the studies were experimental lab studies, some involving nonpilots trained to operate early simulators, while other studies utilized survey data. Most research focused on airline pilots instead of GA pilots. Finally, research is hindered by the lack of data as most NTSB investigations do not exhaustively collect data on Part 91 GA pilot flying history as they do in Part 121 accident investigations.

\section{Instrument Skill Erosion}

Mengelkoch, Adams, and Gainer (1971) studied instrument flying skill erosion using 26 undergraduate nonpilot subjects trained to operate a Link instrument flight trainer. Subjects were divided into two groups that were given training that enabled them to "fly" the Link. After the initial training in which one group received ten training trials and the other group received five training trials, the subjects took a four-month break from training and then retested. The subjects' procedures and instrument parameters were measured and $t$-tests of the results were performed. The authors concluded that, "The most important implication for operational flight training is that procedural responses show retention losses that are not only statistically but practically (operationally) significant whereas measures of proficiency for flight parameters are operationally insignificant" (Mengelkoch, Adams, \& Gainer, 1971, p. 405). While the study is instructive on the influence of inactivity and instrument flying procedures and proficiency, it does not examine the connection to loss of control in IMC.

Childs, Spears, and Prophet (1983) studied low time private pilot skill retention over a twenty-four-month period. Their research linked GA accidents to flying inactivity and skill degradation; however, they did not examine instrument skill proficiency. Their research concluded that the degradation of pilot flying skills contributed to a number of pilot error accidents. Investigators determined that many of these accidents were due to the lack of flying experience by pilots in the months before the mishap and the lack of recent experience in relation to the specific tasks associated with the mishap. According to the study, "the specific relation between loss of flying skills and time is determined by several factors. Such factors include, for example, the type of task that is being performed, the original level of the pilot's skill acquisition, the duration of the time period since the pilot received initial training on the task, and the amount and type of flying done in the interim period since the skill was learned" (Childs, Spears, \& Prophet, 1983, p. 4). Their findings are consistent with Mengelkoch's research.

Mitchell, Vermeulen, and Naidoo (2009) focused on airline crews and analyzed commentaries from three surveys of pilot opinions regarding the introduction of glass cockpit technology. The authors surveyed airline pilots regarding their experiences in automated glass cockpit aircraft. It was found that the population's attitude was favorable toward automated cockpits, but there was a concern that automation would mask a loss of situational awareness among less experienced pilots.

The authors' research focused on the loss of pilot skill attributed to the automated flight deck. Unlike other efforts to quantify erosion of skills due to an absence from flying, Mitchell examined a loss of skill while flying. In other words, they found cockpit inactivity due to automation degraded instrument flying skills. Professional pilots acknowledged the loss of flying skills due to a decrease in hand-flying activities. Their survey comments are below:

- "Pilots can loose [sic] the basic flying skills required due to lack of 'hands on' actual flying."

- "One loses flying skills."

- "I miss the flying!! But realize this is the way to go."

- "But manual flying skills deteriorate over time."

- "Over automated which is, and will continue to degrade the pilots handling skill over time!" 
According to Mitchell, Vermeulen, and Naidoo (2009, p. 22), "Automation does degrade flying skills to a level lower than most professional pilots would like their own level to be." The authors' research is important with respect to automated cockpits and skill erosion and could be a factor in GA instrument flying with increased automation in GA aircraft.

Casner, Geven, Recker, and Schooler's (2014) quantitative research examined 16 B-747-400 pilots using a level D B-747 simulator. The pilots were instructed to fly approaches at a nonfamiliar airport and their performance was measured. The authors measured pilot flight path deviations while they were flying using automated flight systems to control the aircraft, as well as deviations during hand flown segments. The research discovered difficulties among aircrew using VOR navigation instrumentation instead of moving map displays. The research also noted difficulties dealing with three types of instrumentation failure (airspeed, altimeter, and heading indicator). Although most pilots verbalized recognition of the failure, many of the pilots could not effectively handle the aircraft with the instrument failure to within acceptable tolerances. The authors noted problems with pilot cognitive skills while the pilots were coping with instrument failures and found that pilots who stayed mentally engaged with automation performed better than ones who did not. "Task unrelated thought" accounted for nearly $30 \%$ of the variability in performance (Casner, Geven, Recker, \& Schooler, 2014, p. 30).

The NTSB studied glass cockpit avionics and its effects on GA safety (NTSB, 2010). The NTSB used manufacturer records, accident data, and survey data in order to analyze the impact of modern avionics on GA safety. They defined "glass cockpit" as one with at least one primary flight display (PFD) (NTSB, 2010). Today most new aircraft are shipped with PFD/MFD technology and many new aircraft include sophisticated autopilot systems. The NTSB (2010) hypothesized that the introduction of glass cockpit technology in the early 2000s would have a positive impact on GA safety. The NTSB compared aircraft that had both glass and nonglass versions. The report concluded that, while overall "glass cockpit" aircraft accident rates were slightly lower, fatal accident rates were higher. They also noted that glass cockpit aircraft had a higher incidence of IMC accidents that they concluded was marginally significant. They addressed the need for better pilot training and more research to assess avionics reliability. The NTSB reiterated its recommendation from a 1992 special study of PA-46 accidents, recommending the Federal Aviation Administration (FAA) amend 14 CFR 61.31(f) requiring pilots to receive specific training on flight guidance and control systems (NTSB, 2010).

As part of their research, the NTSB (2010) included several case studies. Among them was the case study that is the subject of this paper's research. While the NTSB correctly opined that the PA-46 lost air data due to pitot icing and the pilot subsequently lost control of the aircraft, the Board did not address any pilot actions with respect to training, currency, or checklist usage. In fact, the Board did not address any pilot currency or proficiency issues in their report.

Wright (1973) examined both visual and instrument flying skill erosion in a group of Army pilots. The purpose of the study was to examine cost-effective training methodologies relative to maintaining minimal flying proficiency versus retraining after a significant lapse in flying. Wright surveyed Army aviators who had long periods of nonflying activity or minimal proficiency flying. Wright's survey quantified various flight skills relative to flying versus nonflying activity periods.

Wright noted that inactivity more adversely affected instrument flight rules skills than visual flight rules (VFR) skills where most pilots self-reported less than adequate IFR skills after eight months of inactivity. These results are consistent with Mengelkoch et al.'s (1971) objective study measuring a decline in pilot performance with a period of inactivity from instrument flying. Wright reported almost all skill erosion occurred in 12 months. Comparably, selfreported VFR skills remained above "adequate" for 36 months. Wright (1973) concluded that all standard instrument-rated Army pilots require refresher instrument training every six months. He further concluded that it would be "most profitable to devote all proficiency flying (or the great majority of it) to instrument flying" (p. 16).

Wright's methodology also included survey questions giving the aviators an opportunity to subjectively rate their own flying abilities. Wright noted that "a number of respondents rated their initial flying ability quite high. Most of these pilots would appear to either have an inflated opinion of their flying ability..." (Wright, 1973, p. 7).

\section{Over-rating One's Abilities}

"Over-rating" one's abilities is examined in research where persons with low levels of experience have inflated opinions of their own abilities (Dunning \& Kruger, 1999). Dunning addressed the relationship between overconfidence and incompetence. The study stated, "[n]ot only do these people reach erroneous conclusions and make unfortunate choices, but their incompetence robs them of the metacognitive ability to realize it" (Dunning \& Kruger, 1999, p. 1121).

Pavel, Robertson and Harrison's research (2012) indicates the presence of the Dunning-Kruger effect in the GA pilot population. The authors conducted a two phase study of Southern Illinois University-Carbondale aviation students. In Part Two of the study, students were asked to rate their performance before the FAA knowledge test was given. Knowledge test results were obtained from the FAA and compared to student ranking surveys. The aviation students who scored in the bottom quartile of the tests overrated their performance on the FAA exam. Top performing students underrated their predicted scores, 
while the middle quartiles ranked themselves "fairly accurately" (Pavel, Robertson, \& Harrison, 2012, p. 128). The authors opined that, "when facing a new and potentially dangerous situation, self-confidence is key but over confidence can be catastrophic" (Pavel, Robertson, \& Harrison, 2012, p. 128).

\section{Risk Factors in Weather-Related GA Accidents}

Knecht and Lenz's "Causes of General Aviation Weather-Related, Non-Fatal Incidents: Analysis Using NASA Aviation Safety Reporting System Data" (2010) study is a qualitative and quantitative mixed-methods research approach to discovering causes of aircraft accidents using incident data. The authors used "data mining" techniques to examine one hundred pilot selfreported incident records maintained by NASA. In addition, the authors contacted the incident pilots via NASA ASRS analysts and collected more data and narrative statements not contained in initial reports.

Knecht and Lenz (2010, p. 4) attempted "to identify what kinds of things go wrong when weather enters the picture, to whom those things seem to be happening, how those factors relate to one another and what, if anything, might be done to reduce future risk." They identified ten areas that were problems for pilots, including environmental factors such as weather, dusk, and darkness. Other problem areas for pilots include briefing, forecasting, pilot training, experience, and decision making.

Knecht and Lenz (2010) also divided their study into three levels of pilot certification: ATP-rated pilots, non-ATP instrument-rated pilots, and noninstrument-rated pilots. Their study revealed significant differences in how each group operated with respect to weather. The authors reported that the median pilot in their study had very little experience (heavily weighted toward noninstrument-rated or low time instrument-rated pilots) flying in adverse weather conditions (42-48 hours actual instrument experience and two approaches in the prior 90 days). In summary, the authors concluded that newly-minted instrument pilots are at the greatest risk of incurring a weather-related incident.

In 2005, the NTSB examined GA weather-related accidents. They utilized a case control methodology comparing 72 accident cases to 135 nonaccident pilots who were flying in the same area at the same time as the accident flights. The Board directed their field investigators to collect certain data about the pilots for later analysis. They surveyed the nonaccident pilots. Their quantitative analysis of the resulting data examined pilot age, flying experience, age at first certificate, prior accident and incident history, violation history, practical and knowledge test pass rate history, total flight hours, flight leg length, and aircraft ownership. Remarkably, the NTSB did not determine the pilots' last instrument proficiency check or instrument currency status for either group.

\section{Checklist and Procedural Compliance}

The Federal Aviation Administration (FAA, 1995) published a research report titled, "Human Performance Considerations in the Use and Design of Aircraft Checklists". The report was intended to assist operators in designing, developing, and using aircraft checklists, as well as to "increase awareness of the impact of human performance as it relates to the use of checklists" (p. 1). The literature addressed an NTSB safety study of 37 major accidents of U.S. air carriers between 1978 and 1990. The NTSB study found that in $60 \%$ of the accidents analyzed, procedural errors such as "uninitiated or inadequately performed checklists" (p. 3) were classified as causal to the accidents. Further review by the NTSB revealed "that during the period 1983 to 1993, approximately 279 aircraft accidents occurred where the checklist was not used or followed during Part 91, 121, and 135 operations" (p. 3).

\section{Pilot Training, Pilot Proficiency, and Accidents}

Fanjoy and Keller's (2013) "Flight Skill Proficiency Issues in Instrument Approach Accidents" examined 170 aircraft accident reports that occurred while on an instrument approach with respect to completion of an instrument proficiency check (IPC). Fanjoy and Keller conducted a quantitative study of aircraft accidents that occurred during the approach phase of flight between 2002 and 2012. Half of the surveyed accidents occurred within three and one half months of the last IPC. They stated that a "leading cause of these accidents was a loss of control" (p. 17). Fanjoy and Keller's analysis indicates that these accidents, including loss of control accidents, occurred when the pilots were still instrument "current" and presumably "proficient".

Fanjoy and Keller (2013) sought to "examine general aviation accidents during instrument approach and identify common themes as well as any correlation between the interval between such accidents after initial or recurring IPC" (p. 20). They examined ten years of accident data and identified IPC dates prior to the accident. Of the 170 accidents, they found 31 (18\%) with identified IPC dates. Their research data showed that the mean number of days since an IPC was conducted was 125 days and the median was 111 days. This analysis is noteworthy; however, there is the possibility that many accident pilots had no current IPC logged or the possibility that the IPC was granted fraudulently. There is no analysis of individual pilot logbooks to ascertain pilot instrument experience. A qualitative study complementing Fanjoy and Keller's research would examine the details of GA pilot training and proficiency with respect to temporal passage and skill erosion shedding more light on the issues of currency and proficiency.

Several factors emerge from the literature review: pilot overconfidence in their own flying abilities, poor checklist 
usage and procedural compliance, atrophy of manual instrument flying skills due to autopilot use, and erosion of instrument hand-flying skills due to the passage of time. While these studies identify pilot currency issues related to flying skills, the studies do not conclude that unsafe conditions arise when these conditions are present. They do not reveal in a fine grained manner "why" GA loss of control accidents happen in IMC conditions. The purpose of this case study is to correlate themes from the literature relative to this accident case study and to explore new factors that may not be identified in other research literature.

\section{Methodology}

This research utilizes an exploratory single case study approach. The exploratory case study's purpose is to find undiscovered or unknown themes or factors that may be involved in GA loss of control accidents. These new themes or factors can then be tested in future research.

This exploratory case study uses multiple data sources including ATC audio transcripts, aircraft flight data (NTSB, n.d.a), pilot logbook (Pilot, n.d.), training and FAA certificate records (FAA, 2009), NTSB and FAA accident reports (NTSB, 2009b), numerous physical wreckage inspections, and witness interviews and deposition testimony to define certain events and explore why the accident occurred. The author was a consulting aircraft accident investigator.

Multiple sources of information were triangulated with respect to the accident. The triangulation of information provides for a "convergence of data collected from different sources, to determine the consistency of a finding" (Yin, 2014, p. 241). The digital data from the aircraft primary flight display and multifunction display (MFD) was analyzed with respect to aircraft and pilot operations and compared to exemplar test aircraft results and pilot operating handbook requirements. The pilot logbook was compared to the pilot's FAA certificate documents, SimCom training forms, and statements made by the accident pilot's flight instructors to determine the pilot's experience level.

This case study is bounded by the events leading up to the accident, notably the pilot's training and flying history, the events of the accident day, and related post-accident documentation detailing the accident itself. The following information presented is from official government sources and nonprivileged discovery provided in the litigation connected to this accident. The major themes or factors related to the case included poor procedural or checklist usage, weak pilot proficiency and autopilot usage, improper pilot training, pilot logbook and record irregularities, and poor aircraft systems knowledge. Two themes not found in the literature include improper pilot training and pilot logbook/record irregularities.

\section{Findings}

On Thursday, June 28, 2007, at 08:15 Central Daylight Time (1315 UTC), a Piper PA-46-500TP Meridian, call sign N477MD, broke up in-flight and then impacted terrain west of St. Louis, Missouri. A line of fast moving convective activity, with heavy rain and instrument meteorological conditions aloft, existed at the time of the accident. An IFR flight plan was filed and activated for the accident flight. The private pilot and two passengers were fatally injured. The aircraft was destroyed. The flight was a return leg on a business trip for the owner and his two employees, who were in St. Louis for an ethanol convention (NTSB, 2009a). Aircraft accident reconstruction of events indicates the pilot lost control of the aircraft shortly after the autopilot disconnected while flying in instrument meteorological conditions (NTSB, n.d.b).

One hour before the accident, the pilot called an Automated Flight Service Station (AFSS) to file an IFR flight plan and obtain an abbreviated weather update. During the briefing, the briefer informed the pilot of heavy rain and thunderstorm activity in Missouri along the intended route of flight. The pilot told the briefer that he had onboard radar for weather avoidance (NTSB, 2009a).

The aircraft departed into a line of convective weather just a few miles from the airport. A review of the audio recording of the Gateway TRACON facility, radar, and digital aircraft data revealed the following sequence of events. After takeoff, the pilot immediately deviated north, then west, and flew into an area of heavy precipitation while climbing out of the Spirit of St. Louis (KSUS) airport. The aircraft data and flight path information is consistent with a constant airspeed autopilot climb. The pilot continued his climb on autopilot, through precipitation, but was still below the tops of the cumulus. The aircraft climbed through the freezing level at 13:09:36 UTC at a pressure altitude of 15,831 feet (NTSB, n.d.b). The airspeed indication on the pilot's primary flight display began to decrease 57 seconds after climbing through the freezing level (NTSB, 2009a). This is consistent with icing of the twin pitot tubes blocking the ram air pressure.

\section{Checklist and Procedural Compliance}

While at the hold short line, the pilot is responsible for ensuring the Before Takeoff checklist is complete. "Pitot Heat -On" is part of that checklist. There is no evidence on the multifunction display (MFD) data analyzed after the accident flight that the pilot selected pitot heat at any time during the flight (NTSB, n.d.a). The amperage does not indicate a rise in amperage consistent with pitot heat selection. The MFD in the accident aircraft recorded 4 minutes and 48 seconds of data from the time the pilot began to taxi the aircraft until he added power on the takeoff roll. This data shows that the pilot stopped at the 
hold short line for less than 60 seconds prior to his takeoff roll. The MFD data from the accident aircraft indicates an increase in engine power but no check of the pitot heat or other systems was performed. According to Piper's Flight Test Department, a 13 amp rise is observed when the pitot heat is selected ON during cruise conditions (NTSB, 2009a).

The Engine Run Up checklist procedure calls for the generator and alternator to each be selected OFF and then back ON while checking for the appropriate change in annunciator lights and electrical system load indicated on the MFD (Piper, 2005). The generator and alternator checks would be indicated in the alternator and generator load information recorded in the MFD data. These checks were not indicated in the recorded data post-accident (NTSB, 2009a). Data from prior flights were checked with similar results, indicating the pilot did not routinely perform pretakeoff checklists and turn on pitot heat. This is consistent with poor checklist usage habits by the pilot. There is no evidence from the downloaded aircraft MFD or PFD data that the pilot, upon entering icing conditions, activated the pitot heat, prop heat, or windshield heat according to the Piper checklist for flight into known icing conditions (NTSB, 2009a; NTSB, n.d.b).

Checklists assist pilots in ensuring that the aircraft and its systems are configured correctly for each phase of flight, as well as verifying that all systems are working properly. The accident pilot failed to follow the provided aircraft checklists and omitted crucial steps in the various stages prior to takeoff and after takeoff. Examination of PFD and MFD data from the accident aircraft showed the pilot had a habit of noncompliance with checklist usage on prior flights, as well (NTSB, n.d.b).

\section{Pilot Proficiency and Autopilot Usage}

The aircraft data indicates the autopilot was engaged shortly after takeoff. The autopilot remained on until the pilot disengaged or overpowered it shortly before the airspeed data was lost. The pilot's airspeed indicated zero on the PFD at 13:10:45 UTC, one minute and 9 seconds after climbing through the freezing level. Similarly, the copilot's airspeed began decreasing and indicated zero at approximately 13:10:51 UTC. The autopilot began to pitch the aircraft nose down in an attempt to maintain airspeed when the airspeed began to decrease, since it was engaged in airspeed climb mode (NTSB, 2009a; NTSB, n.d.b). According to S-Tec, the autopilot manufacturer, the autopilot will disconnect if the g loading exceeds $+/-0.6$ g's from normal flight or if the pitch rate exceeds 4 degrees per second (S-Tec, 2004). These limitations were not exceeded until after the direction of the pitch reversed and began to increase at 13:10:43.8 UTC (NTSB, 2009b). The reversal from decreasing to increasing pitch was a result of the accident pilot pulling back on the yoke.

The aircraft digital recorded data downloaded from the Avidyne PFD and MFD shows that the aircraft was unstable due to pilot mishandling of the controls for approximately two minutes prior to the breakup. During that time, the pilot first pitched the aircraft up to a maximum pitch angle of 35 degrees above the horizon (the aircraft then stalled), and then pitched

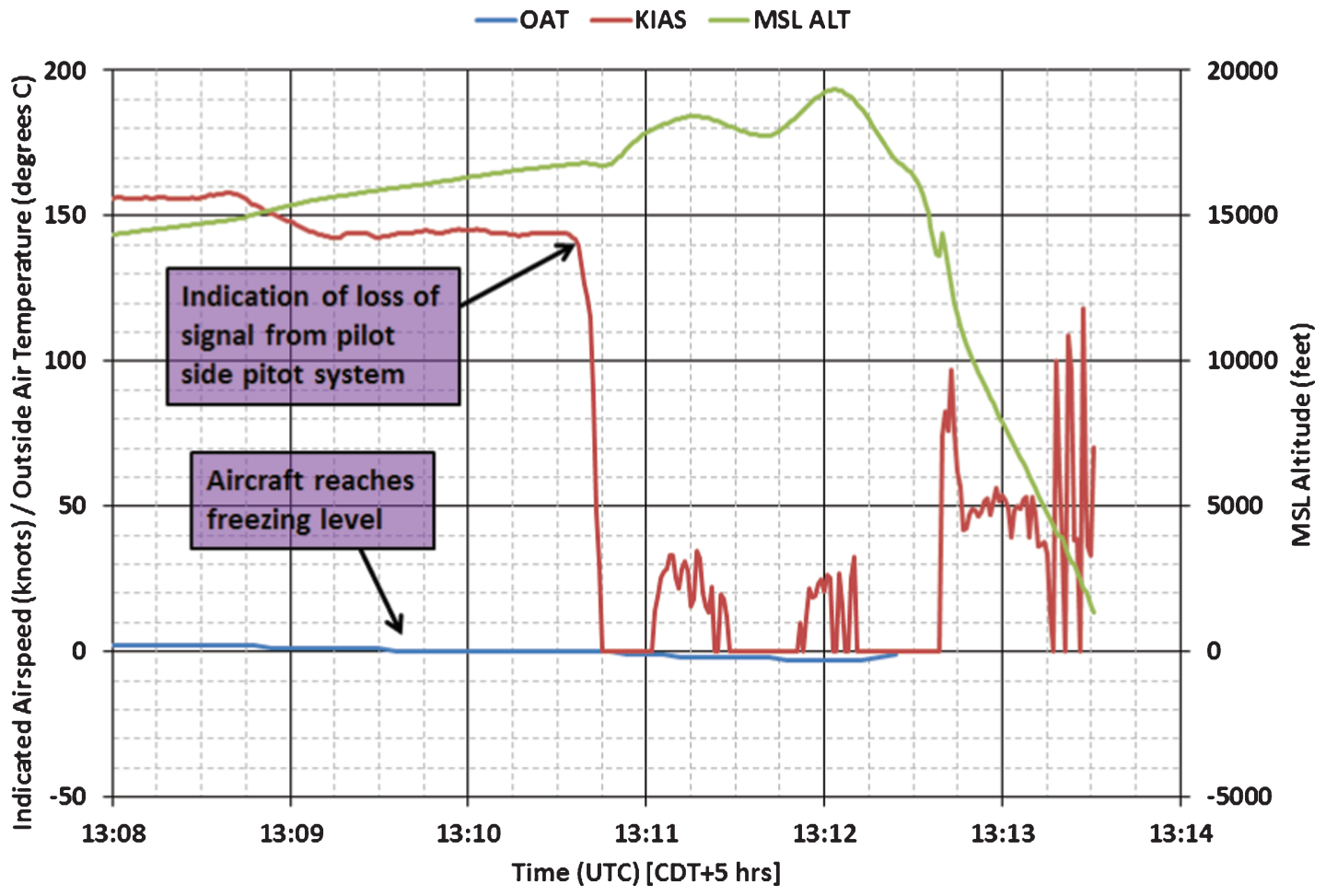

Figure 1. Altitude, airspeed, and outside air temperature-PFD1, MFD. 


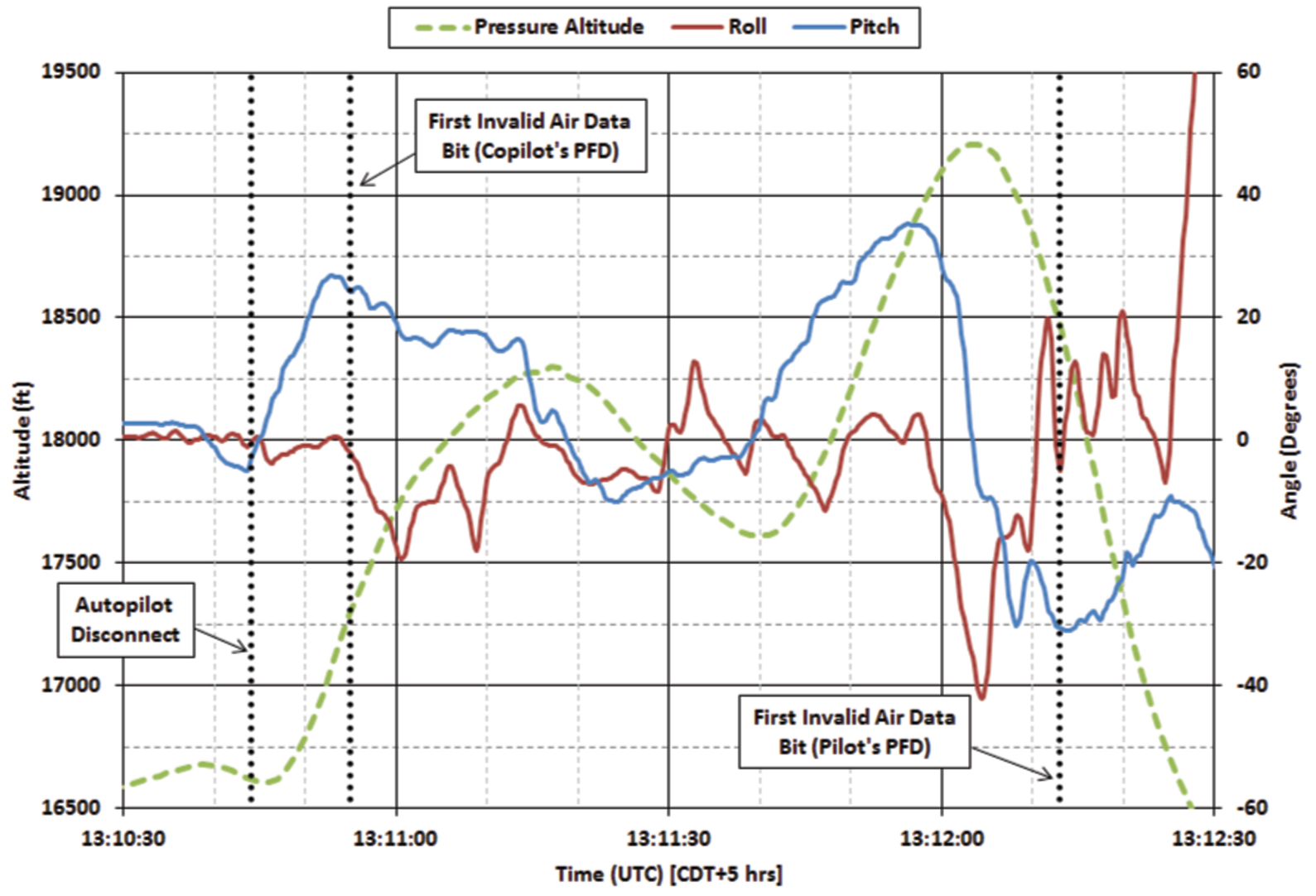

Figure 2. Altitude, pitch, and roll.

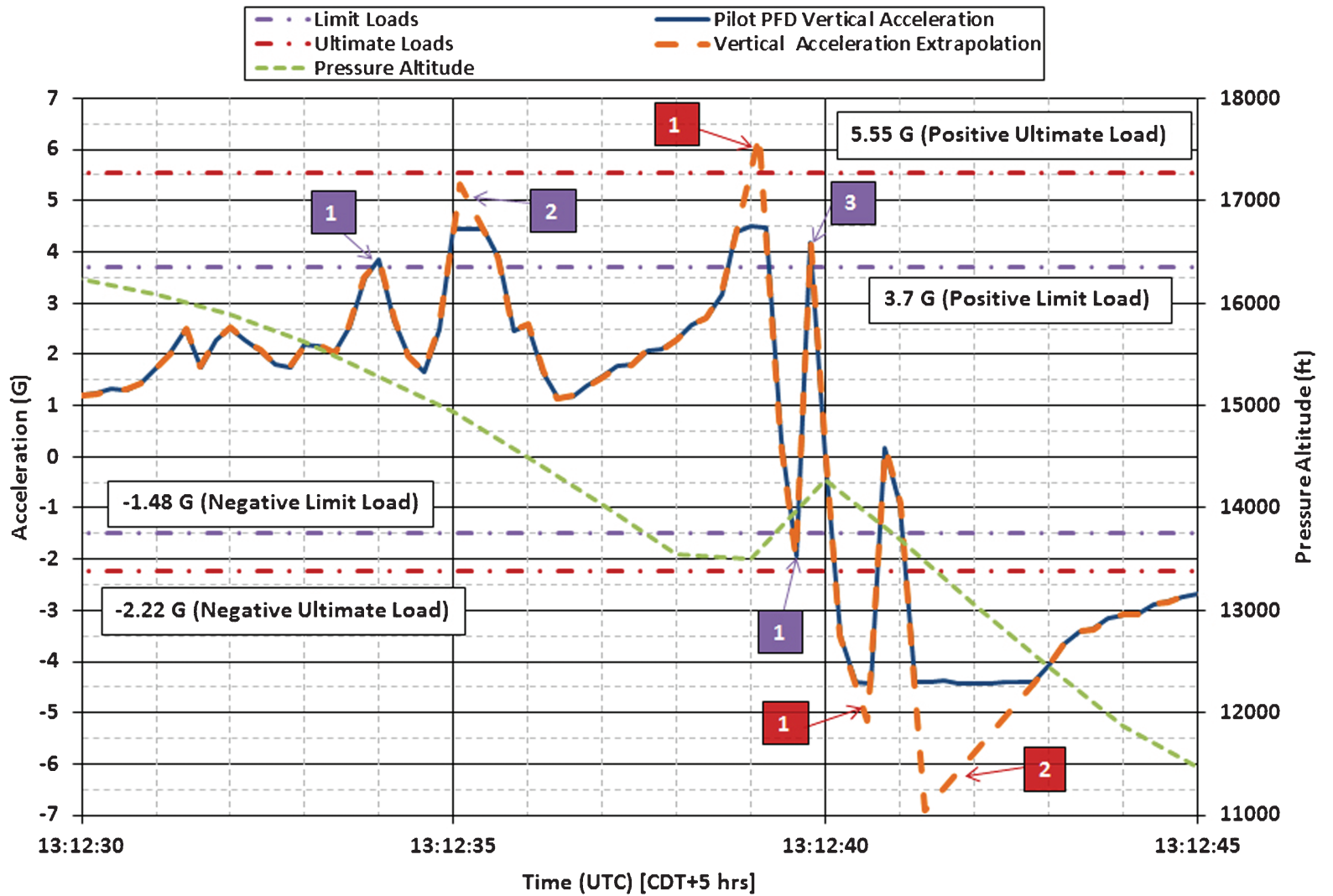

Figure 3. Vertical acceleration. 


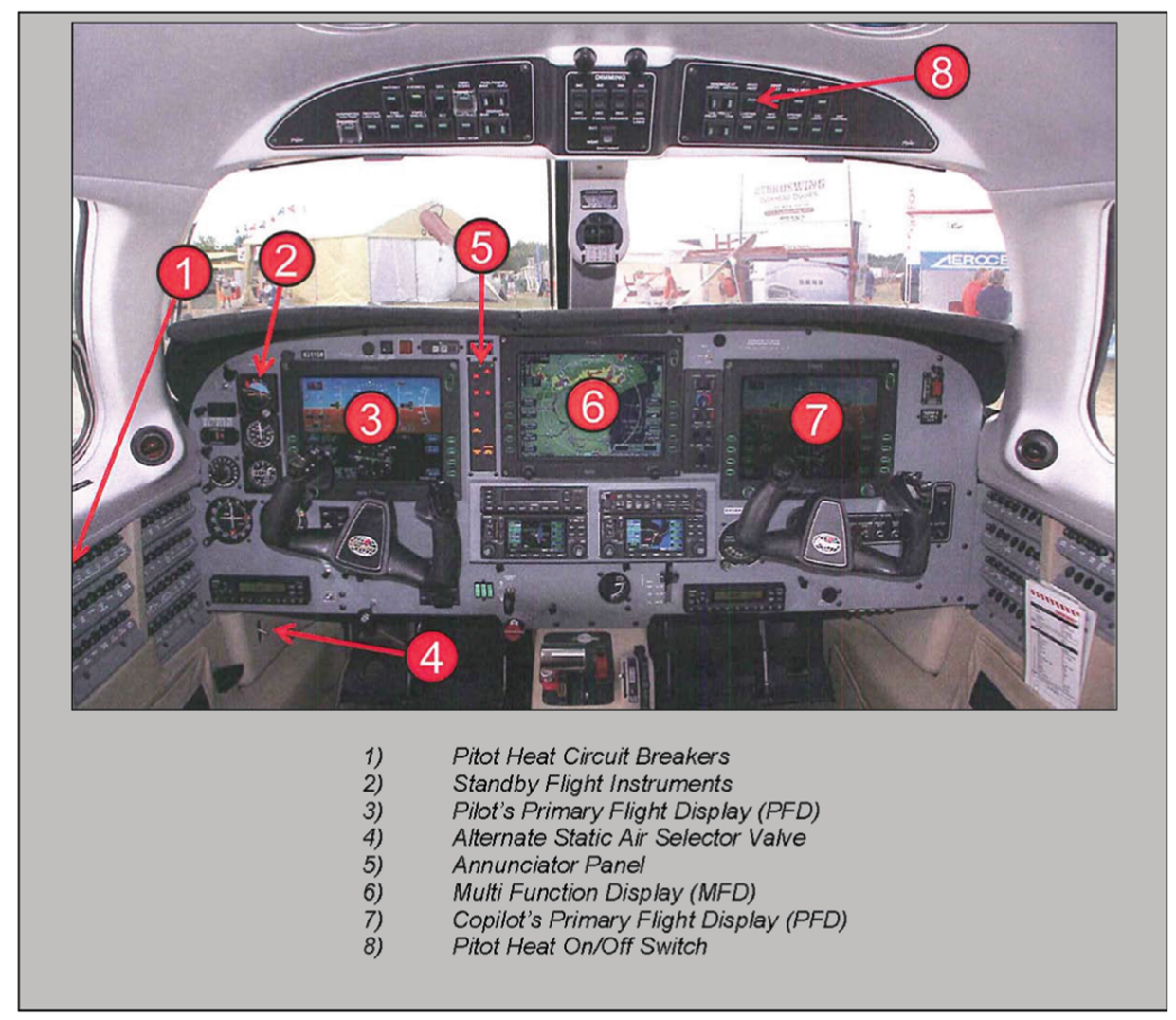

Figure 4. Piper PA-46-500TP cockpit.

down to a minimum pitch angle of -30 degrees, at which point the nose came up briefly but quickly dropped to -87 degrees (nearly straight down). The aircraft roll angles during those two minutes varied from 42 degrees left wing down to 20 degrees right wing down. Right roll increased rapidly immediately prior to the breakup (NTSB, n.d.b; NTSB, 2009b).

The pitch excursions were accompanied by over five positive and negative "g" excursions that exceeded the aircraft limitations causing the wing spar failures (NTSB, 2009a). The loss of control began immediately after the autopilot disconnect.

The in-flight breakup was preceded by a time span of two minutes in which the pilot did not maintain a normal flight attitude by reference to the three working and independent attitude indicators in the cockpit (NTSB, n.d.b; Piper, 2005). The pilot was unable to hand-fly the aircraft in IMC. He overcontrolled the aircraft in pitch and roll. This resulted in overstressing the wings, which caused them to fail (NTSB, 2009b).

\section{Pilot Training}

The pilot was a successful businessman and got into GA later in life, owning a succession of high performance single engine aircraft. His pilot history was reconstructed from Federal Aviation Administration records on file at the FAA record center in Oklahoma City, Oklahoma, including his FAA airman medical records and certificate records. Other records used to reconstruct the pilot history included various training records and flight time recorded with three flight instructors (NTSB, n.d.b). Several of these people were deposed for litigation. The pilot's logbook was also used to reconstruct his flying history (Pilot, n.d.).

The accident pilot was issued his private pilot airplane single-engine land certificate on November 9, 1999, at the age of 37. He applied for an FAA instrument rating on March 25, 2005; however, he failed the check ride. He was immediately given remedial training and subsequently retested and passed (FAA, 2009).

The story the logbook portrays is of a pilot who did not regard instrument currency seriously. He logged five instrument approaches on May 24 and 26, 2005, in connection with his new PA-32 purchase and completion of his instrument rating. He then logged one instrument approach on June 9, 2005, and one on July 11, 2005. The pilot logged 1.1 hours of actual instrument time on July 11, 2005. There is no record of "holding" in his logbook after March 23, 2005. There is no record in the logbook of "intercepting" or "tracking courses"-tasks necessary to $\log$ for instrument currency. The pilot's instrument currency expired on September 30, 2005-six months after completing his instrument rating (Pilot, n.d.).

The accident pilot continued to frequently fly out of instrument currency. He logged an instrument approach 


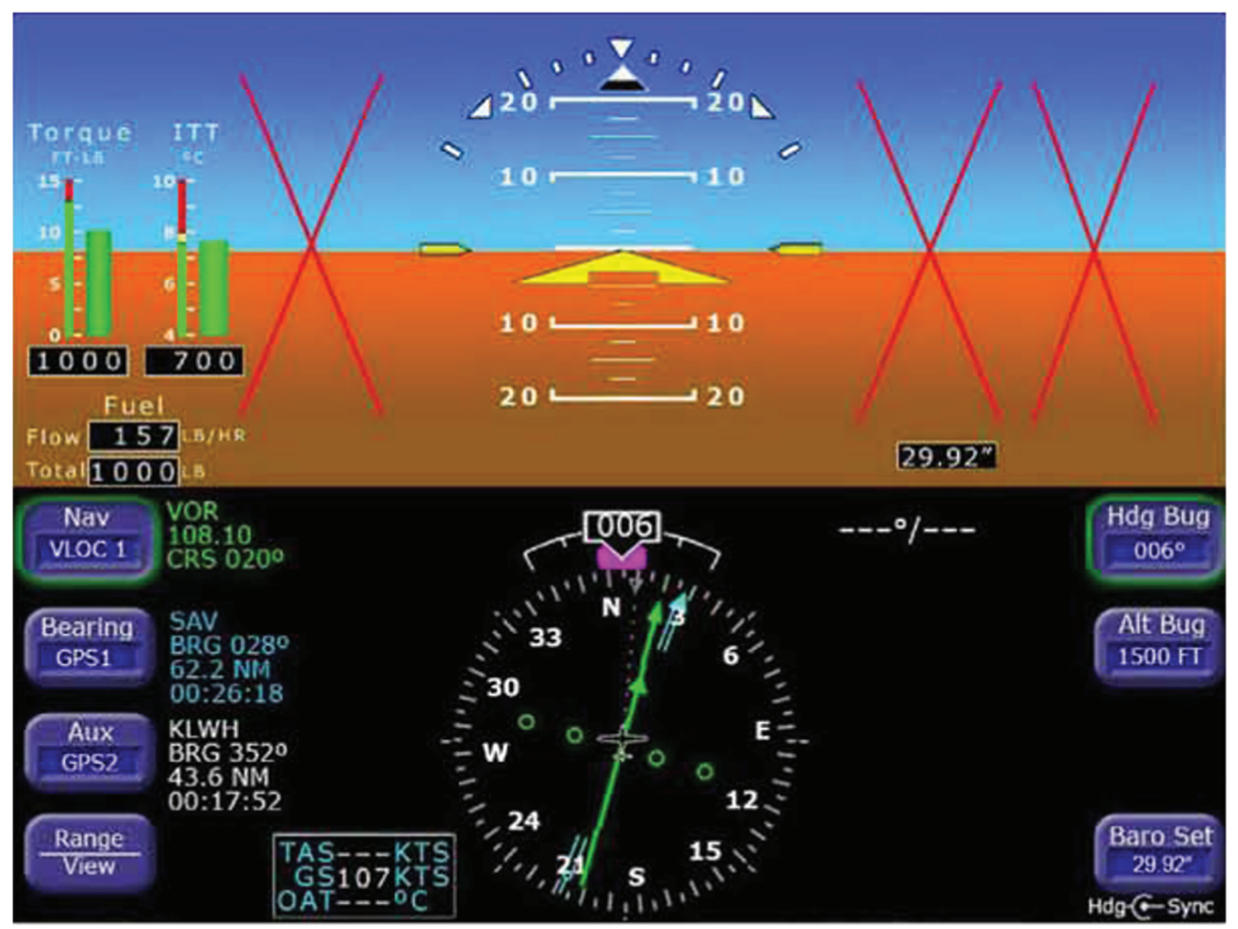

Figure 5. Avidyne PFD—invalid air data (Avidyne Entegra EXP5000 PFD Pilot's Guide, p. 40).

on February 29, March 14, and March 20, 2006, while he was not instrument current. The pilot logged no actual or simulated instrument time during these three approaches. He was either unaware of instrument logging requirements or chose to ignore those requirements. For example, there is no indication in his logbook of a safety pilot onboard the aircraft-required for simulated instrument flight. The pilot did not record the type of instrument approach on any of the approaches flown between May 2005 and March 2006 (Pilot, n.d.). A pilot is required to record the location and type of instrument approach if the approach is to be used to meet instrument experience requirements.
After purchasing the new Piper Meridian in August 2006, the pilot completed a flight training course in the Piper Meridian on August 30, 2006, with an independent contract flight instructor. The flight instructor endorsed him for an IPC on the first day of training in an aircraft the pilot just purchased. They completed just one simulated approach and 0.5 hour of simulated instrument flight time (Pilot, n.d.). This does not meet standards for an instrument proficiency check (IPC) and likely contributed to the accident. Another accident investigation revealed the same instructor gave a similar IPC endorsement to another low time instrument pilot that also resulted in a fatal accident, shortly after the endorsement (NTSB, n.d.a).

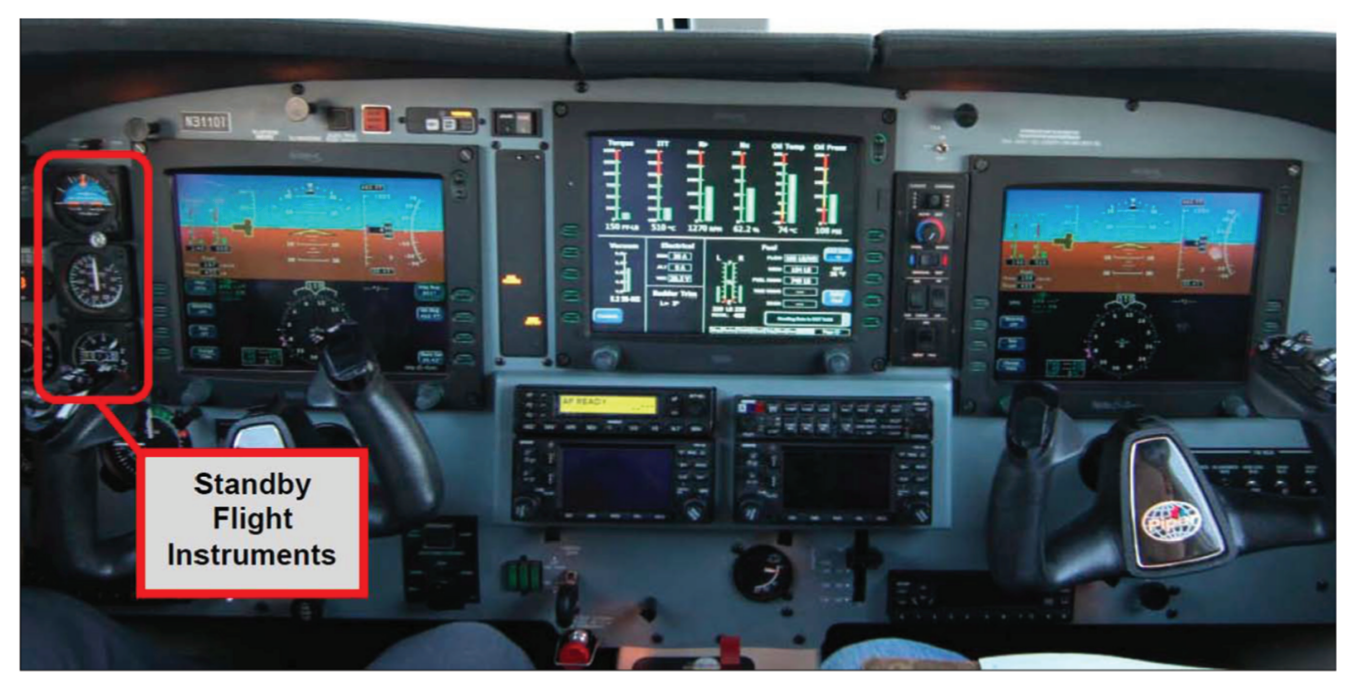

Figure 6. Piper PA-46-500TP cockpit. 


\section{Pilot Logbook Irregularities}

14 CFR 61.57 requires that a pilot must perform and log six approaches, holding and radial tracking in the preceding six months or receive an instrument proficiency check from a Certified Flight Instructor-Instrument (CFII) in order to act as Pilot in Command (PIC) under instrument flight rules. In addition, 14 CFR 61.51 details how a pilot should $\log$ flight time and 14 CFR 61.59 outlines fraudulent logbook entries (U. S. Government Printing Office, 2013). The accident pilot was not legally instrument "current" at the time of the accident.

The pilot attended SimCom training for the Piper Meridian in November 2006, less than 90 days after his training with the instructor (NTSB, n.d.b). The pilot reported on his SimCom pilot history form that he had over 1,000 total flight hours and "300+" hours of instrument time (NTSB, 2009a), when he actually had far fewer hours logged (NTSB, n.d.b). He did not receive an endorsement from SimCom for an instrument proficiency check or a flight review, even though he requested these endorsements be included in his training (NTSB, 2009b). This lack of endorsement by SimCom is consistent with the pilot's failure to successfully meet IPC and flight review standards. When flight instructors withhold requested endorsements in training, it is usually because the pilot cannot meet standards. There was no further training recorded in 2007 prior to the accident (Pilot, n.d.).

The accident pilot demonstrated, via his logbook, a lack of understanding regarding how to properly log instrument flight time and how to maintain instrument currency. $\mathrm{He}$ also demonstrated a willingness to fly IFR while not instrument current. The pilot's last logbook entry was November 23, 2006-seven months prior to the accident. His last logged instrument approach was August 30, 2006 - ten months prior to the accident (Pilot, n.d.).

A young CFI, who did initial operating experience flying in the PA-46 accident airplane with the accident pilot, described the pilot as a confident pilot (Larson, 2008). The downloaded aircraft data from the accident flight shows the pilot was incompetent in flying the PA-46-500TP in instrument conditions (NTSB, n.d.b).

The pilot's last pilot logbook total hour entry indicated he had 248 pilot hours as of May 26, 2005 (Pilot, n.d.). In addition to the logbook, FlightAware data was acquired for the accident aircraft (FlightAware, n.d.). The timeframe spanned June 5, 2005 to June 28, 2007. The FlightAware data, logbooks, and flight data from flights with the young CFI were analyzed to determine the accident pilot's time in type as well as his total flight hours. The analysis indicated that the accident pilot had approximately 667 total flight hours at the time of the accident. The pilot's total time in the PA-46-500TP was approximately 151 hours (Pilot, n.d,; FlightAware, n.d.). All of his time in type was accumulated in the accident aircraft and is consistent with the aircraft records (NTSB, n.d.b). At the completion of training with the independent instructor in August 2006, the accident pilot had approximately 485 hours (Pilot, n.d.; FlightAware, n.d.). Upon completion of his training at SimCom in November 2006, he had approximately 542 total hours-not the 1,000 plus hours he claimed on his SimCom pilot history form (Pilot, n,d,; NTSB, 2009a; FlightAware, n.d.). He logged a total of 2.7 hours of logged actual instrument time after completing his instrument rating in March 2005. At the time of the accident, the pilot had a total of 2.4 hours of logged actual instrument time where he was the only pilot on board. The pilot logbook indicates a total of 10.4 hours of actual instrument time and 31.2 hours of simulated instrument time as of November 2006 (almost all of it acquired in pursuit of his instrument rating) — not the "300+" hours of instrument time he listed on his SimCom pilot history form (Pilot, n.d.; NTSB, 2009a). Thirty percent of a pilot's total flight time logged as actual instrument time is an extraordinary amount of instrument time, and was also likely fraudulently stated on his SimCom registration form. This is likely why SimCom did not endorse the pilot for a flight review and IPC in the Meridian (SimCom, 2006).

The accident pilot was a very inexperienced instrument pilot flying a high performance aircraft. He likely falsely claimed more flight time and experience than he actually had in order to satisfy insurance requirements, since most insurance underwriters would require a pilot have at least 1,000 hours total time in order to be insured in a Piper Meridian.

\section{Aircraft Systems Knowledge}

The Instrument Flying Handbook (FAA, 2001) outlines pilot techniques for flying instruments. These techniques depend on the pilot properly interpreting the aircraft instruments and making proper flight control inputs. The Piper Meridian had two PFDs-one on each pilot side with a large MFD in the center. These PFDs presented airspeed, altitude, rate of climb, attitude, heading, and turn rate, as well as other information, to the pilot. The Meridian also had a set of mechanical standby gauges in a vertical row adjacent to the pilot's PFD (Piper, 2005). The standby gauges give a pilot the means to also fly the aircraft safely under instrument conditions. According to the FAA Instrument Rating Practical Test Standards, pilots are required to demonstrate "basic instrument flight maneuvers under both full-panel and references to backup primary flight instruments/electronic flight instrument displays" on the instrument rating test and during subsequent IPCs (FAA, 2004, p. 14). The FAA expects pilots to maintain these partial panel instrument skills during their instrument flying career.

In this case, the Piper Meridian is classified as a technically-advanced aircraft and has backup flight instruments in front of the pilot. The pilot did not suffer a total loss of basic flight instruments or his PFD when he 
overcontrolled the aircraft. He initially lost airspeed, and then his air data instruments "flagged" on the PFDs (NTSB, n.d.b). He continued to have functioning pilot and copilot PFD attitude and heading instruments, and also a mechanical backup attitude indicator and altimeter that were not affected by the loss of the pitot system (NTSB, 2009a). GPS groundspeed was also presented on the PFD. The loss of airspeed indication was attributed to the pilot's failure to engage the deice and anti-ice systems on the aircraft. Knowledge and application of these systems could have averted the accident.

\section{Discussion and Conclusions}

Was the erosion of the accident pilot's instrument handflying skill present in this case? The training records indicate the pilot did not possess adequate instrument skills. The aircraft data shows that the pilot lost control as soon as the autopilot turned off. Although some data was lost on the PFD, backup information on the PFD and standby instruments provided all the necessary flight information (airspeed and altitude) that was lost.

Did the accident pilot possess an inflated opinion of his flying skills? Documents with inflated flight times and flight instructor testimony indicate the pilot was overly confident in his abilities-in spite of failing an instrument checkride and not obtaining endorsement for an IPC during his latest training event.

This case study explores the themes or factors present in this accident. Two of these factors are not discussed in other research.

1. The pilot did not follow sound checklist procedures. The MFD and PFD data indicate the pilot frequently did not follow proper checklist procedures for flying the Piper PA-46 on the accident day. The pilot not only did not activate pitot heat in icing conditions, but he did not activate any anti-ice or deice systems. This is consistent with FAA research on checklist use and may be a larger problem in GA. This warrants future research to discover the extent of checklist misuse by GA pilots.

2. The autopilot disconnect and the immediate loss of control exhibited was recorded by accident aircraft PFD and MFD data. The pilot immediately pitched the aircraft to plus 35 degrees aircraft nose up. The degradation of the pilot's cognitive and instrument hand-flying skills were likely due to his low total recorded instrument flying experience and his overuse and overreliance on the autopilot following his May 2005 instrument rating check ride. This is consistent with Casner, Geven, Recker, and Schooler's (2014) findings. The investigation of this accident revealed that the pilot was not sufficiently proficient to hand-fly IMC and this phenomena may be more prevalent in GA. This also merits further research.
3. The pilot's initial instrument training in the PA-46 was not performed to standards. He was endorsed for an IPC on his first training flight in the PA-46, logging only one half hour of simulated instrument time. He did not receive an endorsement for an IPC on his subsequent training episode, again suggesting that he lacked instrument proficiency.

4. The pilot likely was overconfident in his flying skills. One instructor described him as very confident pilot. On the accident flight he departed into a line of severe weather that could be seen from the ramp and was offered a deviation around the weather by ATC, but he chose to go through it.

5. The pilot's aviation records indicate a pattern of inflated flight times and experience not consistent with his own logbook. This also suggests he had an inflated sense of his own flying abilities. His logbook was incomplete, and, on face value, indicates the pilot had limited actual instrument experience and was not instrument current at the time of the accident.

6. Finally, the pilot's poor application of aircraft systems knowledge is also evident in the data. Turning on pitot heat could have averted this accident. The yellow pitot heat warning lights on the caution and warning panel were illuminated the entire flight, indicating to the pilot that pitot heat was not activated. Additionally, his habit of not using the anti-ice and deice systems as required by the AFM indicate weakness in his systems knowledge.

As in any study of an aircraft accident, it is usually not one item that leads to an accident, but rather a chain of events that cause an accident. Future research is needed to understand the importance and interrelationship among these factors in other GA instrument-related loss of control accidents. The relationship between instrument flying experience and autopilot usage patterns in GA, for example, needs to be explored further, as one could conceivably have a significant amount of instrument experience, but very little actual "hands-on" time. Such research may lead to regulatory changes regarding instrument "currency" requirements; for example, requiring mandatory IPCs every six months instead of logging instrument experience. Also, single pilot GA checklist usage and systems knowledge requires further research in order to determine the true state of GA pilot knowledge and practice and its impact on GA safety.

\section{References}

Avidyne Corporation. (2007, October 1). Entegra Piper Meridian EXP5000 primary flight display pilot's guide. Rev. 4. Lincoln, MA.

Baxter, S., \& Jack, P. (2008). Qualitative case study methodology: Study design and implementation for novice researchers. The Qualitative Report, 544-559.

Casner, S. M., Geven, R. W., Recker, M. P., \& Schooler, J. W. (2014, May 16). The retention of manual flying skills in the automated cockpit. 
Human Factors: The Journal of the Human Factors and Ergonomics Society. doi: 10.1177/001872081453628

Childs, J. M., Spears, W., \& Prophet, W. (1983). Private pilot skill retention in 8, 16 and 24 months following certification. Pensacola, FL: National Technical Information Service.

Dunning, D., \& Kruger, J. (1999, June). Unskilled and unaware of it: How difficulties in recognizing one's own incompetence lead to inflated self-assessments. Journal of Personality and Social Psychology, 77, 1121-1134.

FAA. (1995). Human performance considerations in the use and design of aircraft checklists. Washington, D.C.: Federal Aviation Administration.

FAA. (2001). The instrument flying handbook. Washington, D.C.: Federal Aviation Administration.

FAA. (2004). Instrument rating practical test for airplane helicopter powered lift. Washington, D.C.: Federal Aviation Administration.

FAA. (2009). FAA airman file pertaining to David Lee McCormick. Oklahoma City, OK: Federal Aviation Administration.

Fanjoy, R. O., \& Keller, J. C. (2013). Flight skill proficiency issues in instrument approach accidents. Journal of Aviation Technology and Engineering, 3(1), 17-23.

FlightAware. (n.d.). FlightAware data for N477MD.

General Aviation Joint Steering Committee. (2012). General Aviation Joint Steering Committee Loss of Control Work Group Approach and Landing. Washington, D.C.: General Aviation Joint Steering Committee (GA JSC).

Knecht, M., \& Lenz, W. R. (2010). Causes of general aviation weatherrelated, non-fatal incidents: Analysis using NASA Aviation Safety Reporting System data. Oklahoma City, Oklahoma: Federal Aviation Administration.

Larson, K. (2008, September 18). Deposition of Matthew Ketcham. Minneapolis, MN.

Maxwell, J. A. (2009). A realist approach for qualitative research. Los Angeles, CA: Sage Publications.

Mengelkoch, R. F., Adams, J. A., \& Gainer, A. C. (1971). The forgetting of instrument flying skills. Human Factors, 13, 397-405.

Mitchell, J., Vermeulen, L. P., \& Naidoo, P. (2009). Flying glass: A qualitative analysis of pilot perceptions of automated flight-decks after 20 years. International Journal of Applied Aviation Studies, $9(1), 13-28$.
NTSB. (2005). Risk factors associated with weather-related general aviation accidents. Washington, D.C.: National Transportation Safety Board.

NTSB. (2009a). NTSB aviation accident database \& synposes. Retrieved March 2, 2014, from http://www.ntsb.gov/aviationquery/brief.aspx? ev_id=20070705X00878\&key=1

NTSB. (2009b). NTSB factual report aviation CHIO7FA183. Washington, D.C.: NTSB.

NTSB. (2010). Introduction of glass cockpit avionics into light aircraft. Washington, D.C.: NTSB.

NTSB. (2013, November 23). NTSB accident database. Retrieved November 23, 2013, from http://dms.ntsb.gov/aviation/AccidentReports/ ssvfyc2mg1q1o1qasozlzy551/R11232013120000.pdf

NTSB. (n.d.a). NTSB: Docket management system/Bradford. Retrieved March 2, 2014, from http://dms.ntsb.gov/pubdms/search/hitlist.cfm? docketID $=49494 \&$ CFID $=220040 \&$ CFTOKEN $=12253516$

NTSB. (n.d.b). NTSB: Docket management system/McCormick. Retrieved March 2, 2014, from http://dms.ntsb.gov/pubdms/search/hitlist.cfm? docketID $=44201 \&$ CurrentPage $=1 \&$ EndRow $=15 \&$ StartRow $=1 \&$ order $=1 \&$ sort $=0 \&$ TXTSEARCHT $=$

Pavel, S. R., Robertson, M. F., \& Harrison, B. T. (2012). The DunningKruger Effect and SIUC University's aviation students. Journal of Aviation Technology and Engineering, 2(1), 125-129.

Pilot. (n.d.). Pilot logbook.

Piper. (2005, May 6). PA-46-500TP Merdian Pilot's operating handbook. Report VB-1912. Vero Beach, FL: Piper.

Prophet, W. W. (1976). Long-term retention of flying skills: An annotated bibliography. Washington, D.C.: United States Air Force.

SimCom. (2006, November 27). Malibu Meridian simulator proficiency training record for David McCormick. Vero Beach, FL.

S-Tec. (2004). S-Tec Magic 1500 Autopilot (P/N 01304) Pilot's Operating Handbook. Mineral Wells, TX: S-Tec.

U. S. Government Printing Office. (2013, October 20). Electronic Code of Federal Regulations. Retrieved from http://www.ecfr.gov/cgi-bin/text$\mathrm{idx} ? \mathrm{c}=\mathrm{ecfr} \& \mathrm{SID}=\mathrm{c} 84 \mathrm{cb} 1 \mathrm{a} 6 \mathrm{aec} 41311390130570 \mathrm{a} 84 \mathrm{f} 3 \mathrm{f} 9 \&$ rgn $=$ div8\&view $=$ text\&node $=14: 2.0 \cdot 1 \cdot 1 \cdot 2 \cdot 1 \cdot 1.36 \&$ idno $=14$

Wright, R. H. (1973). Retention of flying skills and refresher training requirements: Effects of non-flying and proficiency flying. Washington, D.C.: U.S. Army.

Yin, R. K. (2014). Case study research (5th ed.). Los Angeles, CA: Sage Publishers. 